\section{Entrevista: Christian Ingo Lenz Dunker}

Interview: Christian Ingo Lenz Dunker

O psicanalista Christian Ingo Lenz Dunker é professor livre-docente do Instituto de Psicologia da Universidade de São Paulo (USP). Vencedor do Prêmio Jabuti na categoria Psicologia e Psicanálise, com o livro Estrutura e constituição da clinica psicanalítica: uma arqueologia das práticas de cura, psicoterapia e tratamento (Annablume, 2011), tem uma importante obra nessas duas áreas, com publicação de artigos e uma seção nas revistas Mente e Cérebro e Cult. Nesta entrevista, 1 Dunker trata de temas como a atualidade da psicanálise, sua interface com o pensamento dialético, a questão da ideologia e outros temas que contribuem para compreender o mal-estar hoje, em especial, em países de capitalismo hipertardio como o Brasil.
The psychoanalyst Christian Ingo Lenz Dunker is a lecturer professor at the Institute of Psychology of the University of São Paulo (USP). A Jaboti Award Winner in the Psychology and Psychoanalysis category with the book titled Estrutura e constituição da clinica psicanalitica: uma arqueologia das práticas de cura, psicoterapia e tratamento (Structure and constitution of the psychoanalytic clinic: an archeology of the practices of cure, psychotherapy and treatment) (Annablume, 2011), he has done important work in these two areas, publishing articles and a section in the Mente e Cérebro and Cult magazines. In this interview, 1 Dunker discusses issues such as the current moment of psychoanalysis, its interface with dialectical thinking, the issue of ideology, as well as other topics that contribute to understanding the current malaise, especially in countries where there is hyper late capitalism such as Brazil. 


\section{Revista}

Professor Christian Dunker, na sua leitura, qual o papel da psicanálise hoje, em tempos de exposição total da 'vida privada' (via Facebook), de uma nova estetização da política e cujos sujeitos, de maneira quase generalizada, perdem seu objeto, numa espécie de 'presentificação/esvaziamento do desejo'? O mal-estar hoje é um luto coletivo?

\section{Christian Ingo Lenz Dunker}

Durante muito tempo, a psicanálise, como método de tratamento e como discurso sobre a modernidade, foi entendida como uma prática orientada para a expressão e o ordenamento da vida privada. Isso é um engano quando se pensa na psicanálise de Lacan. Um de seus ditos espirituosos afirma justamente que, quando entramos na psicanálise, a diferença entre o público e o privado fica suspensa - o que não deve ser entendido como o endosso da gramática de composição e mistura entre assuntos públicos segundo gramáticas privadas, ou de aparelhamento de temas privados no escopo do interesse público. A psicanálise pode ser bastante útil para pensar a natureza e a consistência dos muros, fronteiras e litorais que se estabelecem nas novas configurações entre espaço público e espaço privado. Além de sua dissociação liberal e de suas retomadas românticas, pensar hoje, por exemplo, a função dos afetos na política - desamparo, medo, piedade, ódio - torna-se crucial. É uma tolice liberal achar que, por exemplo, afetos, desejos ou economias libidinais, de pequena ou grande escala, são assuntos privados e devem ficar restritos à cena da família e da reprodução de práticas sociais. Parte da esquerda também meteu-se em uma espécie de programa de purificação ética, imaginando que boa política se faz apenas com sujeitos que se livraram de seus interesses e paixões, como se a vida privada fosse sinônimo de conservadorismo e de interesses sórdidos que, no fundo, não deveriam existir no verdadeiro homem político. Esse tipo de solução termina em altas doses de idealismo sem substância, na ascensão retrógrada de formas de comunitarismo, na paranoia sistêmica que torna a política um campo de impessoalização para técnicos profissionais. Ora, isso é evidentemente interpretado pelo resto das pessoas, não envolvidas com políticas partidária ou institucional, como um distanciamento e como uma perda de experiência e desconfiguração do campo da política em mero empreendimento administrativo-judiciário. Penso que a psicanálise, mas não só ela, desempenhará um papel importante na redefinição e na retomada do interesse na política para além da atual forma partido-militância.

O mal-estar (Unbehagen), por exemplo, é uma categoria freudiana de grande potência política, não apenas restrita ao tema do luto dos ideais ou causas perdidas, tal como aparece em autores como Zizek, Badiou e Mouffe. O mal-estar implica o reconhecimento de que há formas de sofrimento que não se inscrevem em narrativas categoriais, em pré-formatos discursivos e institucionais, exigidos pelas políticas públicas de amparo, assistência, de saúde ou de educação, de direitos civis e de plataformas ambientais. A pressuposição de que o sujeito político, assim como o sujeito econômico, age racionalmente com respeito a fins, de que ele fará escolhas que necessariamente reduzem prejuízos e maximizam lucros, de que ele no fundo pode ser formalizado por teorias da ação racional, ou por esquemas de reconhecimento pré-fabricados pelas diferentes gramáticas expressivas e estéticas disponíveis, mostrou-se desastrosa e falsa. Há formas de sofrimento que ainda não podem ser nomeadas, existem formas de reivindicação que não precisam saber exatamente o que querem - para preencher o formulário de inscrição discursiva na política institucionalizada. Ora, a psicanálise sempre foi, historicamente, uma prática orientada para o reconhecimento de modalidades de mal-estar antes que ele estivesse normalizado por dispositivos de controle. Desde a crítica da 'moral sexual civilizada' até o repúdio psiquiátrico da imputação de ausência de sentido nos sintomas e ainda a crítica das ilusões de felicidade, sempre se lutou pela irredutibilidade do sofrimento neurótico ao sintoma - supondo que este contém um grão de verdade que o ultrapassa - e do mal-estar ao sofrimento - supondo que este contém contradições maiores do que seria possível apresentar naquele momento.

O esvaziamento do desejo e o sentimento de perda da experiência ocorrem porque o campo político, em determinado momento, só consegue reconhecer demandas, ou seja, formas de desejo reificadas, hipostasiadas, alienadas em narrativas específicas, como aliás mostrou muito bem Ernesto Laclau com sua noção de significante flutuante. 


\section{Revista}

Quais são os limites da relação entre dialética e a psicanálise hoje, uma vez que são duas formas de pensar que têm autores em comum como Lacan, cujo contato com a dialética se deu a partir de um marxista hegeliano ainda hoje pouco conhecido chamado Alexander Koyève?

\section{Christian Ingo Lenz Dunker}

Bem antes de chegarmos aos limites, penso que a relação ente psicanálise e dialética ainda não foi explorada em toda a sua extensão e suas implicações. Antes de tudo, é preciso entender a radicalidade da apropriação que Lacan faz da dialética, pela via de Koyève nos anos 1930, de Hypollite nos anos 1950 ou de Althusser nos anos 1960. Lacan não usava a dialética apenas para falar sobre a teoria do sujeito ou para desenvolver a sua teoria do real - aliás, a sempre esquecida Ciência da Lógica, de Hegel, está tão presente em Lacan quanto a Fenomenologia do Espírito. Lacan afirmava que a psicanálise, ela mesma, como evento histórico e como tratamento, 'é uma dialética', uma verdadeira experiência dialética. O que Lacan procurava em Koyève era no fundo uma renovação ou a introdução de uma teoria do sujeito em psicanálise que estivesse fora do alcance normativo e adaptacionista do conceito de indivíduo ou da rota 'privatista' do eu psicológico. O que vem junto nessa operação é um tipo de antropologia hegeliana que causou alguns efeitos colaterais de longo prazo no pensamento lacaniano, mas que no fundo é uma questão para toda a filosofia francesa que passou pela fenomenologia. No mais, nossa pesquisa no Laboratório de Teoria Social, Filosofia e Psicanálise da USP tem tentado recuperar criticamente a antropologia hegeliana, por meio de uma reconstrução da teoria do reconhecimento que nela estava implicada - veja-se, por exemplo, o recente livro de Vladimir Safatle, Grande Hotel Abismo - ou ainda pela aproximação com alguns autores da antropologia pós-estruturalista, como Viveiros de Castro. Os limites da dialética concentram-se não nas noções de Real ou de 'objeto a', que no fundo descrevem condições e experiência de contraidentidade e contradição, mas em seu emprego com pretensões de totalização. A filosofia da história e a teoria da lógica hegeliana ainda são úteis para praticar diagnóstico social e não para fazer prognóstico político.

\section{Revista}

Alguns autores da sociologia, como Paulo Silveira e Mauro Iasi, percebem uma grande contribuição em algumas categorias lacanianas para entender a ideologia nos tempos de hoje, principalmente ao observarem, como tem tratado Zizek, uma tênue ligação entre a ideologia e a produção de desejos, cuja referência situa-se na distinção/interpenetração que Lacan apresenta na 'composição' ou registro da realidade. Se a questão está formulada corretamente, em que sentido o simbólico teria uma primazia ante o real e o imaginário para compreendermos os fenômenos ideológicos de hoje?

\section{Christian Ingo Lenz Dunker}

A crítica da ideologia estava muito combalida quando Jameson e o pessoal da New Left Review perceberam que ela estava se tornando outra coisa: Cultural Studies, Estudos de Gênero, Teoria Feminista, Análise de Discurso ou meramente teoria estética. Para fazer crítica da ideologia, na esteira do marxismo clássico, teríamos que admitir de algum modo um ponto de vista da totalidade que fosse minimamente sustentável como método. O último que conseguiu foi o Lukács da Teoria da Formação do Romance; depois disso, o metodologismo, a territorialização de disciplinas - da qual se alimenta o produtivismo universitário - e a autoanálise dos fracassos do marxismo tomaram conta de uma certa herança de estudos críticos. Aparentemente a psicanálise, justamente pela sua dificuldade em se tornar uma área disciplinar, por um lado, e sua inermidade para se justificar em termos de método, por outro, escapou de ser diluída nas regras universitárias. Ela baseia-se em uma prática real de transformação direta da experiência, a clínica. Ou seja, em termos de disciplina conseguiu preservar esse ponto de vista, para o qual a teoria ainda importa, portanto, ainda é útil para quem quer fazer crítica da ideologia sem reduzi-la a dogmatismo e visão de mundo mal colocada.

Zizek e os demais autores chamados de pós-lacanianos - Butler, Badiou, o grupo de Manchester, o grupo Esloveno, o pessoal da democracia radical - têm em comum essa ideia de pensar no quadro de uma ontologia negativa, uma crítica social que esteja para além do sujeito contratualista, do institucionalismo - aliás, cultivado pela direita hegeliana - e da ideia da ideologia como 
mero desmascaramento da falsa consciência. Note como todos esses autores repudiam as intenções clássicas de fazer da crítica da ideologia uma espécie de prolegômeno a toda forma de educação possível. Esta é uma ideia que deu errado, ou seja, o escopo prático da crítica da ideologia terminava na elaboração de planos pedagógicos, quando não em métodos de ensino e transformação curricular. Não é possível mais pensar verdadeiras políticas públicas nessa base, sem partir de uma crítica da alienação discursiva, sem a admissão da irredutibilidade do real quer ao simbólico, quer ao imaginário. Zizek inverte a relação inicial pela qual o crítico devia mostrar e indicar os objetos estéticos relevantes, que adquiriam por isso valor social de modelagem e cooptação. Ele não se preocupa com o belo e virtuoso, mas com o lixo industrial, com os filmes menos 'críticos' cuja função de 'esclarecimento' está longe de ser evidente. Pelo menos até o momento mais atual de sua produção, na qual as obras clássicas começam a ter outra função óperas, Kafka etc. -, a teoria do real, do ato e a análise da fantasia ideológica têm esse tom clínico de partir das formas de vida realmente em curso e escavar em seu interior os pontos de desarticulação ideológica. Zizek mostrou que a força da ideologia é semelhante à força que nos prende ao sintoma neurótico e à sua fantasia adjacente, ou seja, a ideologia nos cativa pela economia da satisfação libidinal, também chamada de gozo. Por isso, a estratégia crítica que lhe deve ser aplicada não é apenas a interpretação, mas também o ato.

\section{Revista}

Em que sentido podemos distinguir o pensamento de Lacan dos estruturalistas clássicos como Saussure, Foucault e Althusser e do funcionalismo protoestruturalista do Durkheim de As formas elementares da vida religiosa? Em que ponto seu 'estruturalismo hegeliano', se é que podemos cometer esta heresia, pode contribuir para a crítica da ideologia do marxismo de caris dialético?

\section{Christian Ingo Lenz Dunker}

As diferenças aqui são de vários tipos e incidem de modo diverso quando se considera um autor como Saussure, que estava eminentemente preocupado em desenvolver um método de estudo da linguagem, centrado principalmente em sua descrição de um autor como Foucault, que tanto em sua arqueologia quanto em sua genealogia estava preocupado com o tema da constituição do sujeito e de suas condições em termos de saber e de poder. Para Saussure, a fala estava em segundo plano, pois remetia ao particular psicológico da linguagem; para Foucault, dá-se quase o contrário. Ora, Lacan é antes de tudo um teórico do sujeito e depois disso um autor que pensou a subordinação do sujeito à linguagem, à fala, ao discurso e à letra. Se Foucault teve em vários momentos o horizonte de intervenção política, ele jamais fez disso um mote de sua obra, muito menos Saussure. Pois Lacan é um teórico da ação, da ação clínica e, por contingências inusitadas, da ação institucional ou formativa da psicanálise. Lacan está interessado em produzir certas transformações decorrentes da experiência da fala em análise. E isso significava, por exemplo, passar da alienação à separação, atravessar a suposição de saber que pode nos manter na dominação, examinar as fantasias que nos levam à servidão voluntária, desconstruir as identificações imaginárias que reificam nossa posição como indivíduos - e não como sujeitos -, expandindo o universo da falta, conforme a aspiração ética da psicanálise, novas formas de amar e de desejar poderiam se tornar possíveis. Ou seja, são atributos que se espera de uma análise e que também se espera de uma boa crítica da ideologia, sem que uma coisa se confunda com a outra. Afinal, seria uma crítica da ideologia manque. No entanto, podemos pensar que boa clínica é crítica social feita por outros meios, e que sem as condições de análise do inconsciente pouco se pode esperar além de alienações bem sedimentadas. A definição do estruturalismo hegeliano de fato capta o essencial do projeto de Lacan, mas o caso com Althusser e Durkheim é diferente. Lacan nunca incorporou as teses destes autores especificamente; elas eram mais casos genéricos para se pensar a gênese social do simbólico, no segundo caso, e a teoria dos discursos como coerção, no primeiro. 


\section{Nota}

1 Entrevista realizada por Hellington Chianca Couto, professor docente 1 de sociologia da Secretaria de Educação do Estado do Rio de Janeiro, mestre pela Escola de Serviço Social da Universidade Federal do Rio de Janeiro (UFRJ) e membro do Núcleo de Estudo e Pesquisa Marxista (Nepem-UFRJ), em 3 de outubro de 2012. 